\title{
Disputas de sentido em comunidades de fãs: amor e ódio entre Riverdalians
}

\section{Disputes in fan communities: love and hate between Riverdalians}

\section{Disputas en las comunidades de fans: amor y odio entre los Riverdalianos}

\author{
Clarice $\mathrm{GRECO}^{1}$ \\ Enoe Lopes PONTES ${ }^{2}$
}

\section{Resumo}

Fãs em uma comunidade, ainda que compartilhem seus objetos de afeto, podem mostrar discordâncias. A fim de investigar particularidades nessas disputas, realizamos análise de conteúdo de postagens e interações entre os membros de um grupo no Facebook sobre a série Riverdale, no qual existia tensão entre os membros, relacionada ao personagem Jughead Jones. Entre os principais resultados, destacamos: a centralidade dos conflitos amorosos entre fãs adolescentes; reflexão sobre a relação entre as disputas coletivas e a atuação individual dos participantes; proposta metodológica de observação de disputas a partir de categorias de análise; e validação do papel dos administradores na manutenção da unidade afetiva e da ordem interna da comunidade.

Palavras-chave: Fãs; Comunidades; Disputas de sentido; Riverdale; Jughead Jones.

\footnotetext{
Abstract

Fans in a community can present internal disagreements, even if they share objects of affection. In order to investigate particularities in these disputes, we developed content analysis of posts and interactions between members of a Facebook group about the

${ }^{1}$ Professora do Programa de Pós-graduação em Comunicação da Universidade Paulista (UNIP). Doutora e mestre em Ciências da Comunicação pela Escola de Comunicações e Artes da Universidade de São Paulo (ECA-USP). Vice coordenadora do Grupo de Estudos de Análise de Produtos Audiovisuais (GRUPA). E-mail: claricegreco@gmail.com. Orcid: oooo-0002-2603-6808. ${ }^{2}$ Doutoranda e mestre em Comunicação e Cultura, pelo Programa de Pós Graduação da Faculdade de Comunicação (UFBA). Crítica de audiovisual nos sites Coisa de Cinéfilo, Série a Sério e Chovendo Sapos. E-mail: enoelopespontes@gmail.com. ORCID: oooo-0002-9501-3474.
} 
Riverdale series, in which there was tension between members, related to the character Jughead Jones. Among the main results, we highlight: the centrality of love conflicts between teen fans; reflection on the relationship between disputes and the individual performance of fans; methodological proposal for observing disputes in fan communities based on categories of analysis; and the appreciation of the role of community administrators in maintaining internal order and affective unity among fans.

Keywords: Fans; Communities; Disputes of Meaning; Riverdale; Jughead Jones

\section{Resumen}

Los fans de una comunidad comparten sus objetos de admiración, pero pueden presentar desacuerdos. Con el fin de investigar particularidades en estas disputas, realizamos análisis de contenido de publicaciones e interacciones entre miembros de un grupo de Facebook sobre la serie Riverdale, en la que había tensión entre los integrantes, relacionada con el personaje Jughead Jones. Entre los principales resultados, destacamos: la centralidad de los conflictos amorosos entre los fans adolescentes; reflexión sobre la relación entre las disputas colectivas y la actuación individual de los fans; propuesta metodológica de observación de controversias a partir de categorías de análisis; y la apreciación del papel de los administradores comunitarios en el mantenimiento del orden interno.

Palabras clave: Fans; Comunidades; Disputas de sentido; Riverdale; Jughead Jones.

\section{Introdução}

Ao considerar os fãs de produções midiáticas como grupo dedicado às obras e aos indivíduos de suas admirações, é possível enxergar uma propensão dos mesmos em se unir em comunidades, on-line e off-line, para que possam interagir e trocar informações; são os chamados fandoms ${ }^{3}$. Com o advento das inovações tecnológicas, as conexões entre estes grupos são facilitadas e ampliadas, tornando as trocas mais recorrentes. Dentro desta lógica de encontros expandidos trazidos pelas ferramentas do ambiente digital, características classificatórias e analíticas surgirão e se juntarão ao que já estava vigente para a prática de observação deste e de outros grupos.

É importante ter em mente, ao se estudar uma rede social específica, as distinções entre as diversas plataformas e suas múltiplas operacionalidades, já que cada uma delas fornece ferramentas específicas, possuindo materialidades diversas, o que pode trazer diferentes resultados (DOURISH; MAZMANIAN, 2012; LEMOS,

3 Fandom vem da junção de "fan” e "Kingdom”, em inglês, que pode ser traduzido como grupo de fãs. 
2019). No caso deste artigo, observamos uma comunidade de fãs brasileiros da série Riverdale no Facebook. A partir da análise da comunidade, percebemos postagens referentes a diversos aspectos da trama. Dentre esses elementos, chamou a atenção a frequente disputa em torno daqueles membros que apoiam Jughead Jones e os que não gostam do personagem.

Riverdale (The CW Television Network, 2017-) é uma série estadunidense voltada, majoritariamente, para o público adolescente. Baseada nas personagens da Archie Comics - editora de Nova Iorque de HQs -, o enredo é centralizado na investigação de um assassinato de um adolescente, em uma pacata cidade dos Estados Unidos. Neste cenário, Jughead Jones se insere quase como um detetive, que procura desvendar os mistérios, ao lado de Betty Cooper, com quem começa um relacionamento. As disputas de interpretação sobre Jughead acontecem pelo fato de o jovem fazer parte de uma família considerada perigosa na trama e supostamente levar Betty para caminhos perigosos.

Alguns participantes questionam aspectos morais e conservadores de outros integrantes do fandom, que rejeitam o estilo de vida e comportamento de Jughead, pois ele, muitas vezes, seleciona saídas complexas, como invadir residências e entrar excessivamente na vida de outras pessoas. Além disso, a inclusão e/ou exclusão da Betty em seus planos e as brigas entre o casal fazem com que alguns espectadores o considerem abusivo e tóxico. Por aparecer com frequência no grupo de Facebook, voltamos nosso olhar para as postagens e realizamos análise de conteúdo de comentários relacionados ao personagem Jughead e sua aceitação ou rejeição.

Dentro dessa disputa na comunidade notamos três principais pontos que influenciavam o andamento das discussões: o foco do afeto, o tipo de postagem e os esforços de preservação da ordem na comunidade. O primeiro, foco do afeto, trata do conteúdo das postagens e das divergências de opinião em relação ao personagem, expostas por meio das preferências de cada fã, o que pode causar atritos e controvérsias na comunidade. Tais disputas serão pensadas a partir do exemplo do embate entre apoiadores do personagem Jughead (Jugheaders) e seus desafetos (anti-Jughead ou Jughaters). O segundo ponto de discussão é o tipo de postagem, que pode ser provocativa ou opinativa, ou seja, pode trazer mensagem com compartilhamento de opinião aparentemente neutro ou de provocação intencional. Ainda que ambas gerem debates, o teor da postagem tende a influenciar a amplitude das tensões. Por fim, o terceiro ponto, preservação da ordem na comunidade, aborda a postura dos 
moderadores da comunidade e a reação dos administradores para manter o molde pacífico dentro do grupo e, por consequência, a unidade de afeto entre os fãs da mesma série.

A partir destas observações, buscamos expor neste artigo exemplos destes recortes analíticos de postagens e comentários, a fim de trazer perspectivas qualitativas de debates sobre as disputas em comunidades de fãs. Ainda que muito se tenha estudado neste campo, há particularidades na forma como as discordâncias acontecem nestes espaços que ainda podem ser exploradas. Trazemos aqui alguns exemplos, que envolvem, entre outras questões, uma reflexão sobre a atuação individual do fã e a sua repercussão no coletivo. Há também uma exploração metodológica de observação de disputas a partir de categorias de análise, que podem auxiliar propostas de pesquisas futuras que investiguem as atuações dos fãs e suas interações. Além disso, direcionamos a atenção também aos administradores da comunidade, que desempenham importante papel na manutenção da ordem interna e da unidade afetiva entre os fãs.

\section{Disputas de Sentido em comunidades de fãs}

No campo dos estudos de fãs, as disputas e conflitos entre membros de comunidades ou fandoms, apesar de estarem presentes em diversas pesquisas, receberam abordagens contraditórias. Mesmo nos estudos inaugurais, enquanto Bacon-Smith (1992) ressaltava unidade nas comunidades de fãs, Fiske (1992) analisou as relações dos espectadores com os produtos culturais a partir de suas distinções internas, apoiado em noções de Bourdieu (2008) como identidade, gosto e posição de classe. Também Jenkins, desde seu primeiro trabalho (Textual Poachers, 1992), apontou conflitos entre fãs, atribuídos aos níveis de paixão e entusiasmo contido nas comunidades. No entanto, como aponta Johnson (2017), Jenkins também passou posteriormente a enfatizar o lado consensual e unitário dos fandoms, com seu admitido esforço em ressaltar o lado positivo dos fãs, a fim de desconectá-los da ideia de imaturos e acríticos. Para Johnson (2017), ainda que esse foco inicial positivo tenha sido vantajoso como tática acadêmica, essas abordagens acabaram por subestimar a centralidade do antagonismo no fandom televisivo.

De qualquer modo, a diversidade entre os fãs em comunidades foi abordada por diversos estudos na área, seja nos cinco níveis de atividade dos fãs observado por Jenkins (1992) (modo particular de recepção; particularidade de práticas 
interpretativas e críticas; base para ativismo de fãs; formas particulares de produção, tradição e estética; formação de comunidade), nos níveis de produtividade apontados por Fiske (1992) (Semiótica, enunciativa e textual); nos tipos de fãs sugerido por Sandvoss (2013) (fãs, adoradores e entusiastas) ou mesmo na tipologia de fãs reconhecidas por Lopes et al. (2015) (compartilhadores, produtores, comentadores e curadores).

Unem-se aos esforços de categorização de fãs os tipos definidos por Akpinar e Wennerström (2006), sendo eles: 1) não-irônicos: aqueles integrantes que dedicam investimento afetivo e temporal, levando a atividade como algo de intensa relevância para seu cotidiano; 2) irônicos: não são exatamente fãs das obras que consomem, mas estão ali como figuras que se valem da produção original para utilizá-la como motim de inspiração. Tal distinção dialoga com os apontamentos de Gray (2003), ao destacar os anti-fãs ou não-fãs como relevantes para a compreensão dos fandoms e demais espaços de interação da audiência. Tais distinções podem ser encontradas tanto em fandoms esparsos de produtos massivos ou em comunidades organizadas de obras cult (GRECO, 2019). A distinção entre as diversas práticas é importante para a compreensão do fandom e de comunidades organizadas de fãs como um ambiente heterogêneo e, por vezes, divergente.

Assim, disputas ocorrem porque, ainda que dentro das comunidades exista um interesse em comum, seja demonstrada afetividade e que estejam presentes as características para ser um fã, as trajetórias e as maneiras de interação de cada membro não são as mesmas. Cada espectador tem uma vida pregressa e repertórios individuais que formam diferentes referências e distinções em diversas instâncias, seja social, econômica ou cultural. Ou seja, mesmo com as semelhanças dentro de grupos de fãs, cada comunidade é única e possui integrantes que podem agir distintamente. Desta maneira:

Os fandoms são formados por afiliações voluntárias e temporárias, através de investimento emocional e esforço intelectual. Porém existem várias características que diferenciam cada fã, como por exemplo, níveis de participação, graus de influência, preferências e objetivos. Cada um com suas próprias motivações e peculiaridades. Não se pode pensar neste público como um bloco homogêneo de interesses e comportamento. (REZENDE; NICOLAU, 2014, p.5)

Partindo desta compreensão, notamos que as comunidades de fãs constituem fandoms organizados que possuem critérios, regras e ações distintas. A forma como os 
fãs irão se articular, quais materiais irão aparecer mais, quais as causas específicas podendo ser questões sociais ou não - e quais embates entre eles mesmos são pontos a serem observados pelo pesquisador que analisa aquele grupo. Neste sentido, é possível evocar uma das tantas subclassificações para denominar grupos de fãs, a fim de elucidar o grau de complexidade entre eles.

Dentro desta lógica, podemos afirmar que um fator importante para a compreensão dos fandoms organizados é o de que estes são ambientes complexos, com características diversas, como múltiplos tipos de integrantes e atmosferas, além de tipos distintos de interação. Cada participante acaba por ocupar funções e agir de maneiras diferentes. Existem figuras que assumem posturas de líderes e vão procurar comandar ações e discussões de alguma maneira, como aponta Leal et al. (2017). Existem também os que buscam compartilhar suas opiniões em busca de apoiadores, enquanto outros emitem opiniões que podem, intencionalmente ou não, causar discórdia.

O compartilhamento das práticas de recepção e produção de sentido proporciona uma pluralidade de pontos de vista sobre os textos e narrativas em foco. Dentro desta dinâmica, surgem, naturalmente, diversificados olhares, e deles conflitos que começam a marcar alguns grupos. Como aponta Fish (1992), o ato de interpretar pode ser considerado como algo relacionado ao pertencimento a um coletivo. Assim, o grupo Riverdale Brasil pode ser visto como uma comunidade interpretativa.

Neste agrupamento, organizações, mobilizações e estratégias servem como base de estrutura das relações entre estes indivíduos. O conhecimento geral e específico sobre cultura, produtos midiáticos e da obra em si cria distinções e nelas surgem os possíveis atritos (CURI, 2015). Os níveis de engajamento, de permanência e saídas também são elementos que traduzem comportamentos dos fãs dentro de seus grupos. É neste mundo particular de cada fandom que aproximações e distanciamentos são configurados. Abordamos aqui as disputas de sentidos, pois elas revelam algumas das rupturas de um coletivo que supostamente se une em um local por possuírem o apreço, a identificação e a dedicação semelhantes, mas que apresentam discordância acerca de um ou mais pontos da narrativa.

Assim, são promovidas discórdias, o que pode vir a causar um afastamento de algum integrante, como é o caso de membros que saem ou são retirados do grupo. Esta forma de interação pode ser pensada antes como uma construção de coletivos que vão se formando, também, a partir de uma afinidade de gostos que vão se afinando e 
colocando indivíduos em determinados grupos. De acordo com Fish (1992), a obra original não tem a ver com seu resultado "sozinha”. Os consumidores, ao entrarem em contato com ela, criam estes olhares, que existem a partir das vivências e referências deles mesmos. Assim:

(...) um texto qualquer depende não da pré-existência de significados determinados ligados ao texto, mas da inserção dos interlocutores dentro de um mesmo sistema interpretativo e de uma mesma comunidade interpretativa. Isso inclui as circunstâncias, crenças e suposições que cercam a produção do texto. Noutros termos, a comunicação se dá dentro de situações que supõem uma estrutura de pressuposições e práticas relevantes com relação a objetivos e propósitos pré-existentes. (FISH, 1992, p.191).

Essa partilha de crenças une e faz com que as informações compartilhadas dentro dos coletivos sejam potencialmente semelhantes. Para Fish (1992), os grupos sociais seriam determinantes para a interpretação de uma obra. Apesar de o texto existir por si só, a partilha de valores e crenças geraria uma visão influenciada, deslocando o significado do autor e trazendo à tona a interpretação da recepção. Desta maneira, ao encarar os membros que apoiam o personagem Jughead (Jugheaders) e os que não o apoiam (Anti-Jughead ou Jughaters) como comunidades interpretativas partimos do pressuposto de que os fãs são indivíduos com traços de gosto em comum, porém distintos entre si e, portanto, suscetíveis a divergência.

Como vimos, essas disputas, que externam opiniões, afetos e divergências, são corriqueiras em comunidades de fãs e, por consequência, também permeiam as comunidades de séries com público adolescente. O público jovem e adolescente é frequentemente foco de pesquisas por ser um nicho de audiência ativo nas redes mesmo enquanto os programas estão sendo exibidos. Conforme atesta Curi (2015, p. 116), “os jovens prolongam a experiência fora da janela de exibição ou até mesmo a antecipam, entrando em contato com filmes e séries e outros produtos da cultura popular massiva”.

Pontes et al. (2016) elenca casos nos quais fandoms ficaram mais conhecidos por suas brigas pelo sentido "original" da obra. Comunidades voltadas para séries televisivas como Vampire Diaries (The CW Television Network, 2009-2017), Once Upon a Time (American Broadcasting Company, 2011-2018) e Lost (American Broadcasting Company, 2004-2010) são algumas das que mais apresentam públicos que criam tensões dentro do espaço virtual. Outro exemplo pode ser retomado de quando o fandom do seriado de TV Lost declarou guerra, por parte dos fãs acreditar 
na resolução do conflito central da trama, através das ações de um personagem específico, John (homem de fé, bem visto por suas falas e ações).

Enquanto isto, outros davam razão a Jack (chamado 'homem da ciência”). A discussão era pautada, basicamente, em debater se os mistérios da ilha mostrada na narrativa eram algo humano e realista ou do mundo da fantasia. A partir desta situação, o embate estava formado e as disputas de sentido aconteciam, principalmente, nos fóruns e enquetes da plataforma. Os casos de Vampire Diaries e Once Upon a Time são um pouco diferentes do que aconteceu em Lost, pois estão diretamente ligados à questão de formação de pares românticos dentro destes seriados.

Assim, eles estavam mais voltados para o que é chamado de ship war. Ship vem da palavra em inglês relationship que, em português, que dizer "relacionamento". War vem de "guerra". Logo, aqui, fala-se em embate de torcida por casais distintos. Em ambas, a principal discussão estava voltada para o final da protagonista e com quem ela deveria ficar. As intensas e fervorosas discussões buscavam não apenas uma afirmação e conquista de espaço entre eles, mas, também, chamar a atenção dos produtores da obra original, para demonstrar o clamor pelo resultado almejado. Assim, existe uma procura de alguns fãs por terem suas vozes escutadas, uma vez que “(...) reconhecimento e legitimidade são dois dos principais propulsores do trabalho desenvolvido pelos fãs na internet” (CASTILHO; PENNER, 2017, p.223).

Essas características não são exclusivas dos fandoms das narrativas seriadas citadas. Justamente por isso, servem como exemplo para a linha argumentativa que trazemos neste artigo, acerca da série Riverdale. Dentre as características observadas na comunidade Riverdale Brasil ficou nítido que existe uma separação de ordem semelhante. Divididos entre o amor e o ódio ao personagem Jughead Jones, membros do fandom tentam vencer o embate discursivo para ver quem está certo sobre o jovem e qual será seu rumo na trama. Em 2019, no período da quarta temporada, há o mistério sobre a sua morte, o que causou a empolgação de uns e o lamento de outros. $\mathrm{O}$ acontecimento acirrou as disputas de sentido entre estes espectadores, que colocavam a saída ou a permanência de Jughead como uma possível resposta para seus clamores. Essa divergência de opiniões gera a disputa que é objeto deste artigo.

\section{A comunidade Riverdale Brasil no Facebook}

Partiremos, agora, para a apresentação dos dados empíricos coletados e categorizados por meio de análise de conteúdo. De acordo com Bardin (1977), a 
categorização é a passagem de dados brutos para dados organizados, a partir de um processo de reagrupamento pelo qual os elementos de um conjunto são reconhecidos, classificados e diferenciados segundo a categoria, refletindo os propósitos da investigação.

A análise de conteúdo das publicações na comunidade foi organizada, conforme recomenda Bardin (1977), em três fases: seleção dos documentos a serem submetidos à análise, formulação das hipóteses e objetivos e, por fim, a elaboração de indicadores para fundamentar a interpretação dos resultados. As fases da análise dessa pesquisa contemplaram a seleção do corpus, a exploração do material, classificação em categorias, tratamento dos resultados e a referida análise. O objeto de estudo foi selecionado por se tratar de um fandom popular e que possui uma interação mais intensa dentro das redes sociais, principalmente na plataforma escolhida para este artigo. Por esta razão, foram selecionados os fãs da série Riverdale (The CW Television Network, 2017-), por sua popularidade tanto com um público mais abrangente quanto com nicho específico (juvenil).

De acordo com informações do canal que exibe a produção, o seriado tem uma média de 1,5 a 2 milhões de espectadores por episódio, mantendo esta média desde o seu primeiro ano ${ }^{4}$. Nas redes oficiais, a quantidade de seguidores no Facebook alcança 2,5 milhões e no Instagram cerca de 12 milhões5. Além de possuir uma quantidade estável de espectadores e um número alto de seguidores, os grupos de Facebook têm uma interação constante e uma grande quantidade de postagens. $O$ espaço selecionado para a observação que gerou a análise foi um grupo de Facebook, chamado Riverdale Brasil. Ele possuía, no período de coleta, aproximadamente 240 mil participantes, sendo 17 deles administradores da página. Para fazer parte deste coletivo é necessário curtir a fanpage @RiverdaleBra e, em seguida, é solicitado que todas as regras sejam lidas.

Normas sobre convivência, gentileza e cuidado com os colegas de fandom são prioridades. A escolha da comunidade se deu, principalmente, pela quantidade de postagens diárias feitas pelos integrantes. O Facebook foi escolhido por ser uma plataforma que possibilita interações em ambiente fechado, se assim for escolhido pelos integrantes. Nesse formato de grupo, os membros conseguem interagir sem o

\footnotetext{
4 Esse número se baseia na primeira transmissão do episódio, feita pela $\mathrm{CW}$, em rede aberta. Não contabilizando o público dos canais streaming, por exemplo.

5 Todos os números de redes sociais foram checados até o dia 05 de setembro de 2020, às 22 h10.
} 
olhar de terceiros. Outra razão para esta seleção vem do fato de as informações ficarem disponíveis de forma mais acessível, contribuindo de maneira mais efetiva no processo de encontro de publicações anteriores e posteriores ao período no qual a pesquisa para o presente artigo foi iniciada. Durante a coleta de dados, foram registradas interações e situações entre os fãs para posterior tabulação. Além disso, as publicações referentes ao tema deste trabalho foram printadas e arquivadas em uma pasta digital. De toda maneira, a fim de prever possíveis necessidades futuras, a barra de ferramenta se faz útil para a recuperação de publicações dentro da comunidade analisada.

A entrada no grupo aconteceu no dia 22 de setembro de 2019. Durante a análise, que ocorreu de outubro de 2019 a janeiro de 2020, foi observado que, no período de exibição do seriado, as publicações de cada dia variavam entre 20 a 40. Já em época de hiatus $^{6}$, este valor caía um pouco, indo de 10 a 207. Assim, de outubro até dezembro, quando Riverdale estava no ar, foram vistos, em média, mil postagens. No mês seguinte, no tempo de pausa, foram contabilizadas, aproximadamente, 200 publicações. Questões externas à narrativa em si, como o falecimento de um dos atores da obra ou o lançamento de uma temporada no canal streaming Netflix também foram fatores que acentuaram o número de interações, podendo afetar a quantidade de material colocado na página. Obras originais feitas pelos fãs, como fanfictions e fanarts não foram um traço forte desta comunidade que, em sua maioria, apenas compartilhava artes de perfis do Facebook e outras redes sociais. No entanto, manips ${ }^{8}$ e memes eram criados e utilizados para ilustrarem as publicações.

Por essa dedicação e interação, o grupo foi selecionado para a realização desta pesquisa. Além disso, durante observação prévia notamos que neste fandom existe o traço da divergência de opiniões que gera embates intensos e discussões longas. Apesar dos esforços dos administradores do grupo, as discussões sobre torcidas por casais e rumos da narrativa muitas vezes fogem do controle. Entre os dados observados, foi possível perceber que existia uma quantidade acentuada de postagens diárias e que a maioria estava relacionada com o debate sobre as personagens e os rumos da trama, principalmente no que se referem aos pares românticos.

\footnotetext{
${ }^{6}$ Hiatus: pausa, por exemplo, entre o final de uma temporada e início da próxima.

${ }^{7}$ Este dado foi um número calculado pela rolagem de página, em seguido anotado em um documento de Word, feito como uma espécie de diário de campo. Como a quantidade de postagens é extremamente intensa, pode existir uma pequena variação para mais ou para menos durante os dias nos quais o grupo foi observado.

${ }^{8}$ Manip é uma abreviação da palavra manipulação. O termo é utilizado para tratar de imagens que foram modificadas através de programas de computador e aplicativos.
} 
O assunto que mais apareceu foi, de um lado, a paixão de uma parte da comunidade em relação à personagem Jughead Jones e, de outro lado, um desconforto em relação a ele. Na narrativa, Jughead é o narrador, quem decide falar no jornal de escola sobre os crimes que ocorrem em sua cidade. Ele também protagoniza momentos de tensão na história - como a descoberta de que seu pai faz parte de uma gangue ou em sua forma de se relacionar com a mocinha Betty Cooper. Na medida em que as postagens eram publicadas, foram surgindo, com frequência, discussões que demonstravam a rivalidade entre aqueles que admiram Jughead e aqueles que consideram o rapaz uma figura tóxica.

Essa percepção inicial sobre um dos embates mais presentes na comunidade levou ao direcionamento da análise, que revelou três principais pontos a serem discutidos. O primeiro surge do conteúdo da publicação, que por vezes era direcionado ao personagem, outras vezes ao casal Jughead e Betty ou, ainda, em relação ao ator que o interpreta. A divergência entre o foco do afeto dos fãs (neste caso, os apoiadores e os haters do personagem Jughead). O segundo ponto é o tipo de participação e teor das postagens levando a uma breve análise qualitativa sobre o conteúdo das postagens que geraram reações dos fãs. Por fim, o terceiro ponto que pode ser percebido diz respeito à administração da comunidade e às intervenções desta disputa para manter a ordem interna. Foi também encontrada a necessidade de criação de categorias descritivas, para que os indivíduos observados fossem mais bem compreendidos.

Por se tratar de análise qualitativa, os resultados aqui apresentados não visam generalização, mas podem contribuir para reforçar a percepção das comunidades de fãs como espaço de interações entre indivíduos (portanto, dotados de subjetividades distintas), ainda que unidos por afetos comuns. Intencionamos, também, evidenciar que as postagens unem a expressão de uma opinião individual a uma intencionalidade, o que influencia diretamente o rumo dos debates no fandom.

\section{O foco do afeto: Jugheaders x Anti-Jughead (ou Jughaters)}

Interpretado pelo ator Cole Sprouse, Jughead é um adolescente marginalizado por vir de um lado da cidade mal visto por seus demais habitantes. O garoto namora com a protagonista, Betty Cooper. Juntos, os dois investigam os mistérios que acontecem dentro do enredo. A partir da premissa geral e das subtramas desenvolvidas na produção sobre Jughead, os fãs reagiam de distintas maneiras e revelavam seus sentimentos no Riverdale Brasil através de imagens e textos. Para compreender qual 
a dimensão quantitativa da pesquisa, contabilizamos as menções sobre Jughead, dividindo-as em três categorias: publicações exclusivamente sobre Jughead Jones, postagens sobre Jughead e Betty, que formam o casal Bughead 9 e, por fim, aqueles que falavam sobre o ator Sprouse. Como é exibido nos gráficos a seguir:

Gráfico 1 - Postagens relacionadas a Jughead ${ }^{10}$
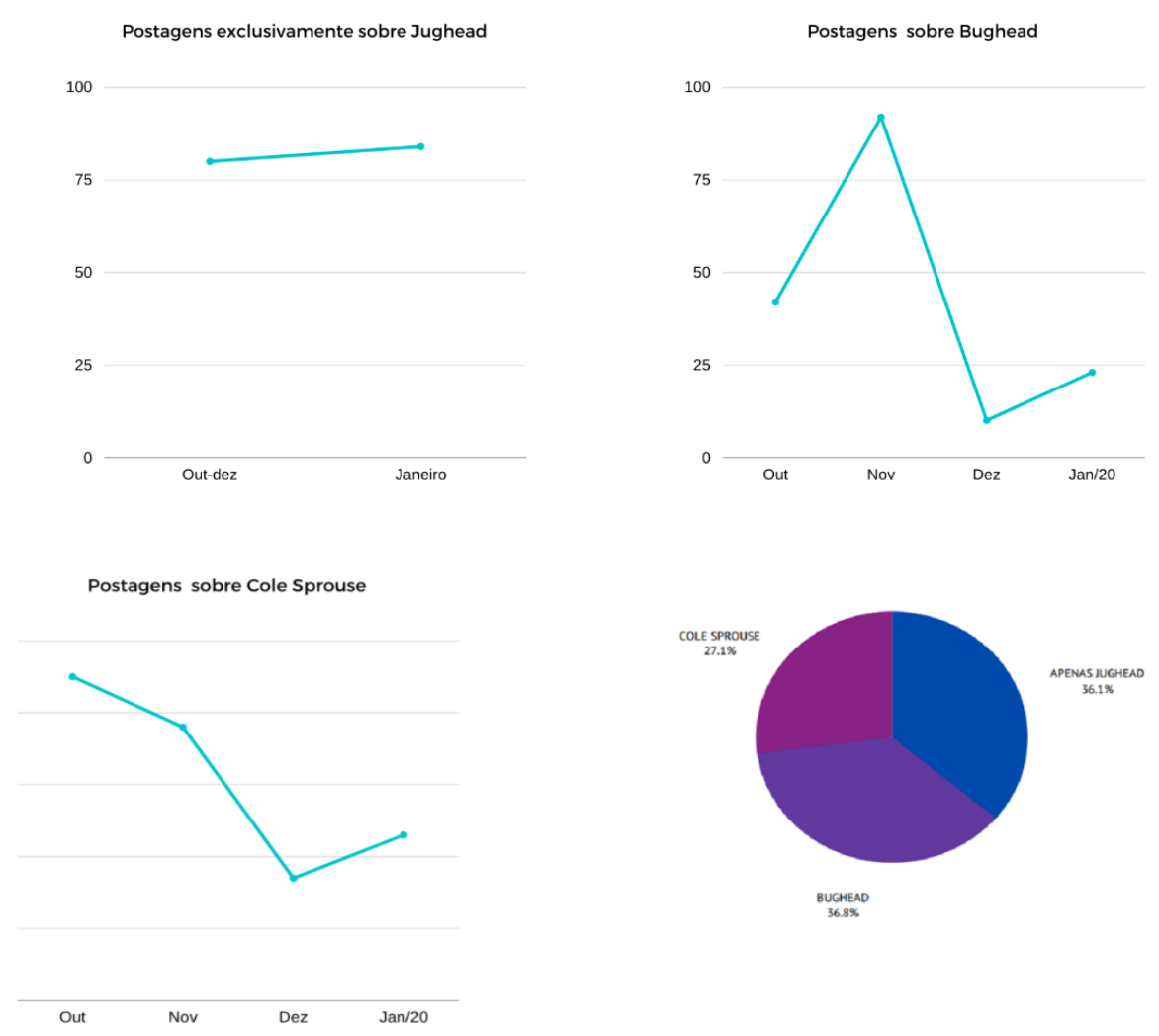

Fonte: Elaborado pelos autores com base em dados do Facebook (2021).

Observamos, através dos números, que o foco principal dos participantes da comunidade era o relacionamento de Betty e Jughead, com um total de 167 publicações entre outubro de 2019 e janeiro de 2020. Ainda que a diferença seja sutil, o número corrobora com pesquisas que apontam os relacionamentos e a prática de shipping como sendo grande foco entre fãs adolescentes no Brasil (CASTILHO; PENNER, 2017; BORGES et al., 2019). A atenção especial aos conflitos românticos é compatível com os fandoms adolescentes em geral. Nessa idade, a vida romântica é parte fundamental do

\footnotetext{
${ }^{9}$ Bughead é o nome dado para o casal Betty Cooper e Jughead Jones. O termo é a junção do nome dos dois.

${ }^{10}$ Gráficos produzidos em setembro de 2020.
} 
convívio social (STENGEL; MOREIRA; LIMA, 2015), e as disputas podem fazer parte da descoberta e afirmação de suas ideias e esperanças sobre o amor.

Em seguida, aparece a categoria que engloba discussões sobre outros elementos que envolvem Jones, com 164 publicações neste mesmo período. Em terceiro lugar, estão as 123 postagens sobre o intérprete Cole Sprouse. A partir destes dados quantitativos, observamos os comentários para compreender quais temáticas em relação a Jughead Jones estavam sendo abordadas. Nessa visita às discussões de cada publicação, passamos a perceber que existia uma espécie de separação dentro do grupo, relacionada à afetividade em relação ao Jughead. Havia uma tensão dentro da comunidade de tal forma que a dividimos em dois subgrupos: Jugheaders e AntiJughead (ou Jughaters). O primeiro termo é popular entre os fãs do seriado Riverdale como um todo. Assim, esta nomenclatura aparece dentro e fora da comunidade analisada.

Ela se refere aos fãs de Riverdale que gostam da personagem Jughead. Já a segunda foi por nós criada com o intuito de classificar este outro lado dos fãs que possuem um afastamento ou aborrecimento em relação a Jones ${ }^{11}$. Os fãs deste segundo grupo se comportam como anti-fãs (GRAY, 2003), pois ainda que sejam apreciadores da série, atuam como antagonistas nos debates acerca do personagem ao qual se opõem e demonstram seu desagrado, acionando conflitos entre os membros.

O nosso objetivo foi deixar mais nítidas as características deste grupo e quais são as rivalidades vividas por eles. Em relação ao par romântico vivido por Jughead e Betty foi possível notar que uma parte do fandom demonstrava gostar da relação da dupla e aprovava como eles resolvem os conflitos que vivem. Outra parte vê o casal como abusivo, com elementos tóxicos e não aceita as escolhas das personagens para a resolução dos problemas. Neste contexto, a partir de postagens dentro do grupo Riverdale Brasil, os embates entre os integrantes desta comunidade aparecem. O hate $^{12}$ e a defesa para Betty e o par romântico apelidado Bughead tem uma frequência recorrente dentro do número geral de publicações, como já apontamos.

Desta maneira, inserimos no presente trabalho os embates interpretativos que envolviam todas as menções à Jughead durante o período de análise. Pudemos perceber também, a partir da observação das postagens e das interações provocadas

${ }^{11}$ Para esta classificação foram apenas considerados os indivíduos integrantes do Riverdale Brasil.

12 Hate, em inglês quer dizer ódio. A palavra é utilizada popularmente para denominar menções de sentimentos de negativos em relação a alguma coisa. 
por elas, que o embate se intensificava ou se mantinha amistoso a depender do teor ou tom das publicações ou comentários. Para compreender se o tipo de postagem e a forma como o fã expressa sua opinião interferem na amplitude da divergência e na forma como ela é conduzida, voltamos o olhar às publicações que mais geraram disputas.

\section{Tipos de publicações: provocativas $x$ opinativas}

A partir da constatação da subdivisão dentro da comunidade e da observação de suas publicações, notamos duas categorias de estilos de postagem, as quais denominamos opinativas e provocativas. A primeira está relacionada às publicações que abordam a personagem Jughead Jones em assuntos diversos, como seus romances, suas aventuras e gostos, entre outras características dele e seus caminhos na trama. Estas postagens têm seu conteúdo voltado à expressão de fatos, notícias ou de opinião particular, aparentemente sem a intenção de causar rivalidade. No entanto, algumas vezes, elas acabam abrindo discussões sobre Jughead e até mesmo conflitos. Já o segundo termo, provocativas, engloba postagens que ofendem Jughead Jones de alguma maneira ou que trazem reclamações diretamente sobre os fãs ou haters da personagem ou do ator. Estas, muitas vezes, são interpretadas de forma provocativa e geram calorosas discussões, que suscitam ações dos administradores da página, como alertas, desligamento da possibilidade de comentários e banimentos do grupo.

Cientes de que todo tipo de categorização carrega certa subjetividade do pesquisador, ressaltamos que a criação de categorias foi uma ferramenta de organização da análise (CARLOMAGNO; ROCHA, 2016), com o intuito de aprofundar o entendimento sobre os possíveis motivos de intensificação das disputas entre fãs. Deixamos nítido também que as categorias não pretendem supor a intenção de quem postou, mas sim trazer uma percepção acerca da reação que tais postagens geraram nos participantes. Por fim, notamos que o objetivo dessa categorização não é de estabelecer uma análise quantitativa e comparativa, mas sim ajudar a direcionar o olhar qualitativo para uma questão que se mostrou relevante na compreensão da disputa em questão, isto é, a natureza dos conteúdos postados e o potencial para gerar debates.

A consideração do tom da postagem, para além do foco no tema abordado, pode auxiliar a análise empírica de disputas internas em fandoms de outras séries. Durante a observação, foi possível notar que havia também um jogo de poder para ver quem 
tinha mais voz e conseguia mobilizar seus pares. A cada postagem, os Jugheaders bradavam defesa ao personagem e marcavam outras apoiadoras para se unirem em sua defesa. Ao marcarem outras fãs, estas eram convocadas para a batalha, tornando-se essa uma estratégia de confronto. Os comentários contra Jughead igualmente convidavam reforços, mas havia uma disparidade entre os Jughearders e os AntiJughead, uma vez que a defesa a Jughead se fazia presente tanto nas postagens opinativas quanto nas provocativas. Aparentemente os defensores de Jughead comportavam-se como fãs não-irônicos (Akpinar e Wennerström, 2006), para os quais a participação na comunidade tem investimento afetivo e de grande relevância.

Os Jughaters, por sua vez, ao criticarem a personagem atuavam como anti-fãs da personagem (GRAY, 2003). Assim, aparentavam sentir uma tensão dentro da comunidade e, a partir disto, provocavam estes embates através desta personagem, pois conseguiam trazer certa animosidade naquele espaço. A seguir, exemplificamos uma postagem opinativa. A autora compartilha um sonho e explicita seu afeto pelo personagem Jughead, revelando ser seu personagem favorito. Consideramos a postagem opinativa pois a fã se pronuncia a partir do olhar pessoal sobre um elemento da série, não menciona a disputa e não traz pergunta ou questionamento direto que convide outros membros a emitirem outras opiniões. A postagem gerou 89 comentários até o momento da pesquisa.

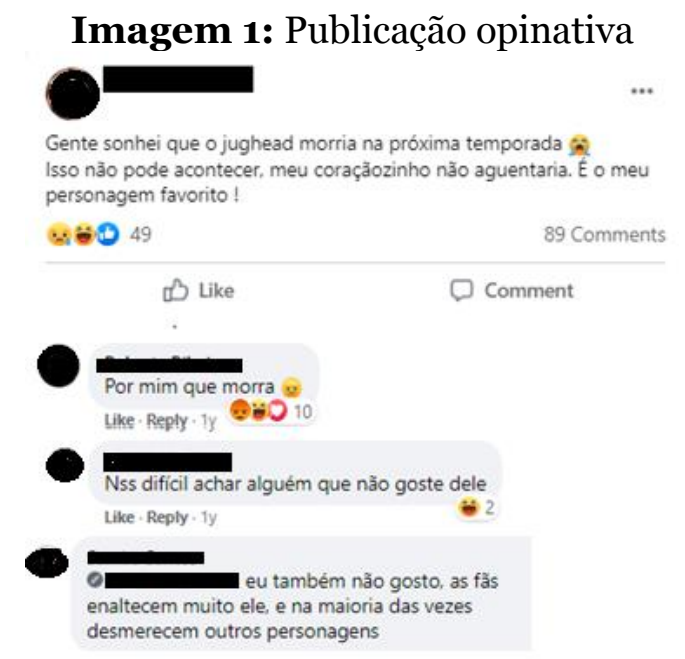

Fonte: Captura de tela da página de grupo do Facebook Riverdale Br, em janeiro de $2021^{13}$

${ }_{13}$ Link da postagem original:

https://www.facebook.com/groups/406590873417021/permalink/515595822516525 
Através desta publicação notamos dois tipos de postagem e de comentários. A publicação opinativa, acima, com aparente objetivo inicial de desabafo sobre o futuro da personagem, se tornou um espaço para relembrar o desgosto por Jughead, seguido de alguns protestos de seus fãs, que parecem incrédulos ao constatar a existência de antipatia por ele. O primeiro comentário em destaque na imagem ("por mim que morra”) externa com ênfase a discordância com a autora da postagem, ao que outra fã responde com surpresa por não esperar encontrar alguém que não goste de Jughead. A partir daí, outras membras do grupo se envolvem na discussão e evidenciam a clara falta de unanimidade em relação ao personagem. Esta publicação demonstra que o tema Jughead Jones pode convocar embates, ainda que a postagem inicial não possua tal intencionalidade.

Por outro lado, uma vez com o conhecimento da disparidade entre Jugheaders e Anti-Jugheads, surgem postagens que se referem especificamente ao embate, buscando reunir ou prolongar a discussão a respeito. Em outras palavras, a postagem se faz espaço de discussão sobre a própria disputa, sendo chamadas aqui de postagens provocativas. Por exemplo, na imagem abaixo (postagem provocativa), apesar de antecipar uma ressalva dizendo estar compartilhando uma opinião, a autora não emite comentário sobre personagem ou elementos da série. O teor da postagem é de discordância dos fãs que apoiam e enaltecem o personagem Jughead. Assim, a postagem não é uma manifestação sobre o objeto de afeto, ela se refere à disputa já existente no grupo e, por consequência, tensiona a opinião do fandom de apoiadores de Jughead. A autora da publicação demonstra um tom de afrontamento ao citar expressões como 'baba-ovo', 'fãs obcecadas' ou o pedido de 'parem'. Ao expor sua opinião sobre as atitudes de outras fãs, pressupõe-se consciência da possível instauração de conflito. A postagem gerou 242 comentários até o momento da pesquisa, nos quais os membros do grupo se dividiram entre defender Jughead e concordar com a postagem. 
Figura 2 - Publicação provocativa

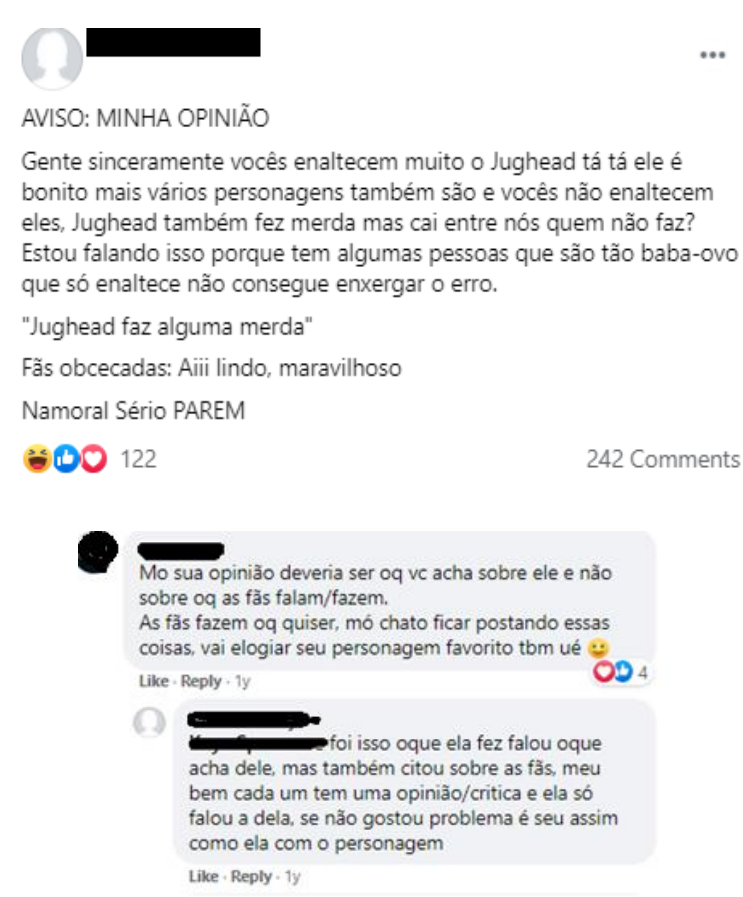

Fonte: Captura de tela da página de grupo do Facebook Riverdale Br, em março de $2021^{14}$

O comentário em destaque na imagem aponta a diferença entre opinar sobre o personagem e opinar sobre as fãs. Esse ponto é crucial para entendermos as dimensões dos conflitos internos, uma vez que o debate deixa de ser sobre a série em si e passa a ser sobre o comportamento dentro da comunidade. Se alinharmos tais atuações à classificação de Sandvoss (2013), os membros da comunidade comportam-se como adoradores, pois criam laços, mesmo que desorganizados, com outros que partilham esse fandom. Não são, portanto, apenas indivíduos fãs que consomem um produto cultural de maneira pulverizada, tampouco entusiastas ao ponto de terem a produção de conteúdo, artes e textos como principal atividade. O cerne da participação está nas interações, opiniões e laços desenvolvidos - de proximidade afetiva com aqueles que compartilham da mesma opinião, ou de embate com os que apresentam discordância.

Como qualquer ambiente de sociabilidade, a comunicação nos grupos de fãs envolve não apenas assuntos sobre o objeto de afeto, mas também sobre comportamentos e relações dentro do próprio ambiente. Falar sobre as posturas de outros membros, indignar-se e surpreender-se com contraditórias opiniões é parte intrínseca de comunidades de interesse. Ao mesmo tempo, dois principais fatores

14 Link da publicação original:

https://www.facebook.com/groups/406590873417021/permalink/510318163044291 
contribuem para a coesão do grupo: um da agência, da performance individual, ou seja, a atuação do fã, seu tipo de envolvimento e suas formas de expressão; e outro da estrutura, da administração, referente à proposta do grupo e atuação dos mediadores, como será visto em capturas de tela de algumas postagens, expostos adiante.

\section{A ordem interna: moderação da disputa}

As comunidades no Facebook são geridas por administradores e moderadores. Ambos têm o poder de aprovar ou solicitar pedidos de entrada na comunidade, aprovar ou negar publicações no grupo, remover publicações ou comentários, remover ou bloquear pessoas, fixar ou desafixar uma publicação para que fique visível por mais tempo para ingressantes do grupo. $\mathrm{O}$ administrador tem ainda funções que o moderador não tem, a saber: alterar a função de usuários dos grupos ou retirá-los e gerenciar as configurações do grupo (nome, foto, descrição etc.). São os ocupantes desta função que, a partir de intervenção na comunidade, acabam por modelar o perfil do grupo e estabelecer o tom da convivência interna, podendo ela ser livre para embates e discussões, ou controlada para fins de prevalência da ordem e suposta manutenção a unidade promovida pelos laços afetivos. Funcionam, também, como fãs curadores (Lopes et al., 2015), por terem influência sobre o conteúdo da comunidade, ainda que seja permitida postagem por qualquer integrante.

Na comunidade Riverdale Brasil notamos que, no ambiente de disputas, os Jugheaders se sobressaíram, inclusive em números - devido às ações dos 17 administradores, dado que estes em diversos momentos baniam aqueles membros que provocavam rivalidade. Outra ação que afastavam os Anti-Jugheads eram os alertas de bloqueio do grupo, que desmotivavam a participação destes indivíduos, que escolhiam sair da comunidade. $O$ fato foi observado através de uma materialidade oferecida pela rede social Facebook. Quando um membro é retirado ou sai do local, o seu nome passa a ficar na cor cinza. Desta forma, quando acompanhamos os embates dentro das publicações provocativas, observamos que alguns nomes passavam a mudar de cor, sinalizando que aquela pessoa não fazia mais parte daquele espaço.

Desta maneira, percebe-se que a ação dos gerenciadores da página é presente e há uma busca em manter um ambiente com o menor grau de tensões e embates. Em mais de um exemplo é vista a necessidade de retirar a possibilidade da comunidade de falar dentro da publicação. O usuário busca divulgar o seu desagrado em relação à 
Jughead e Betty, causando um descontentamento e/ou irritação nos outros participantes da comunidade.

Os exemplos ilustrados em capturas de tela a seguir constituem exemplos ilustrativos da atuação dos moderadores da comunidade. As postagens selecionadas, além de gerarem quantidade intensa de interações incisivas dos integrantes, abarcam em si questões que estavam espalhadas pontualmente em algumas outras publicações. Elas são, portanto, exemplo de medidas mais drásticas tomadas pelos moderadores acerca de discussões que já apareciam em outros postagens, de maneira mais branda. A imagem 4 ilustra e comprova a atuação por meio de comentários desativados, demonstrando também que os comentários estavam desconectados das possíveis intencionalidades dos autores das publicações. Assim, estas imagens aqui trazidas revelam este embate e como ele ocorre.

Figura 3: Publicação com comentários desativados
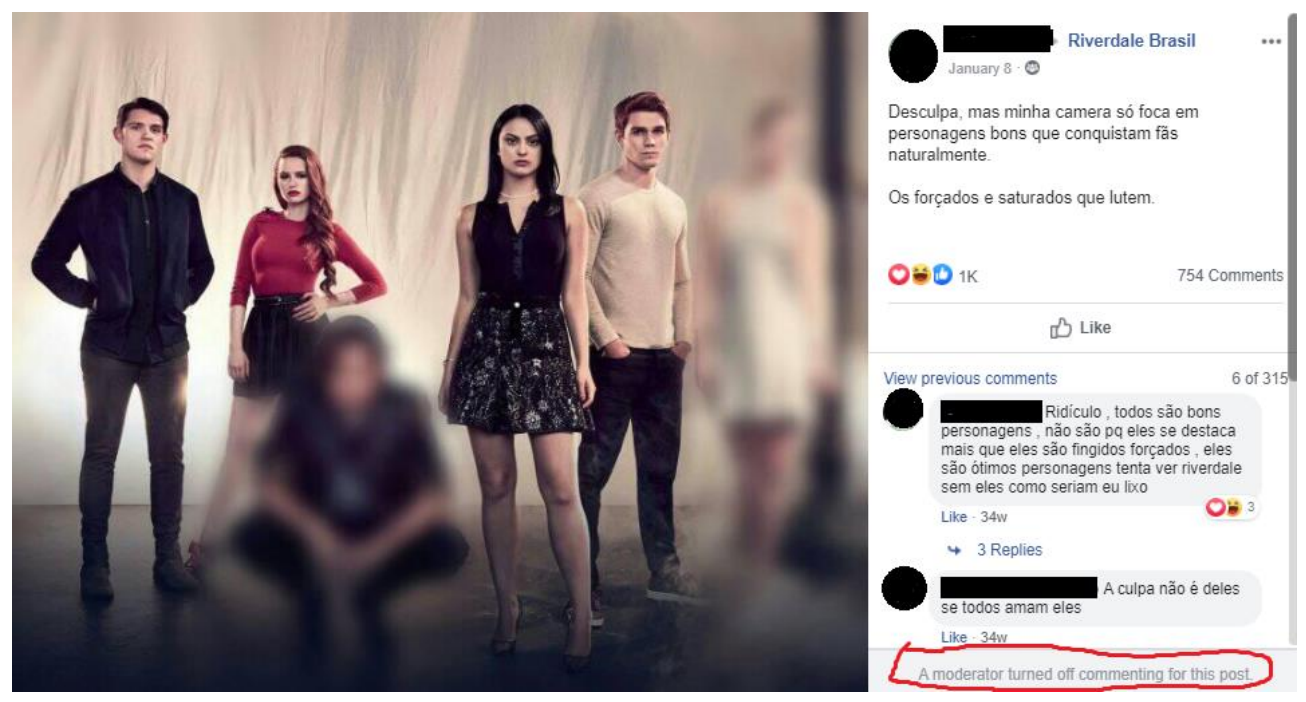

Fonte: Captura de tela da página de grupo do Facebook Riverdale Br, em setembro de $2020{ }^{15}$

$\mathrm{Na}$ Imagem 4, vemos uma publicação de janeiro de 2020, na qual integrantes do grupo Riverdale Brasil debatem a popularidade da personagem, com opiniões distintas. A seleção desta imagem ocorreu por ser uma clara ilustração de como um moderador age diante de um conflito dentro do grupo que ele considere desrespeitoso. A partir da publicação o embate se estabeleceu. Uma vez que o grupo é composto de fãs com opiniões diferentes sobre o personagem em questão, uma postagem que retira

15 Link publicação original:

https://www.facebook.com/groups/RiverdaleBrasilgrupo/permalink/2492577950967048/ 
da imagem alguns personagens e afirma que sua câmera só foca em 'personagens bons' traz em si uma provocação para chamar a discussão em torno de quais personagens seriam ou não 'bons'.

De fato, os comentários apareceram. Alguns concordavam e outros discordavam da opinião do integrante do grupo que fez a postagem provocante. As tensões ficaram tão intensas que um dos administradores retirou a ferramenta de comentários. Como podemos ver na captura de tela posterior, havia um equilíbrio entre defesas para Jughead e concordância sobre a falta de qualidade da personagem dentro da trama.

Imagem 4: Alguns comentários da publicação vista na Imagem 3

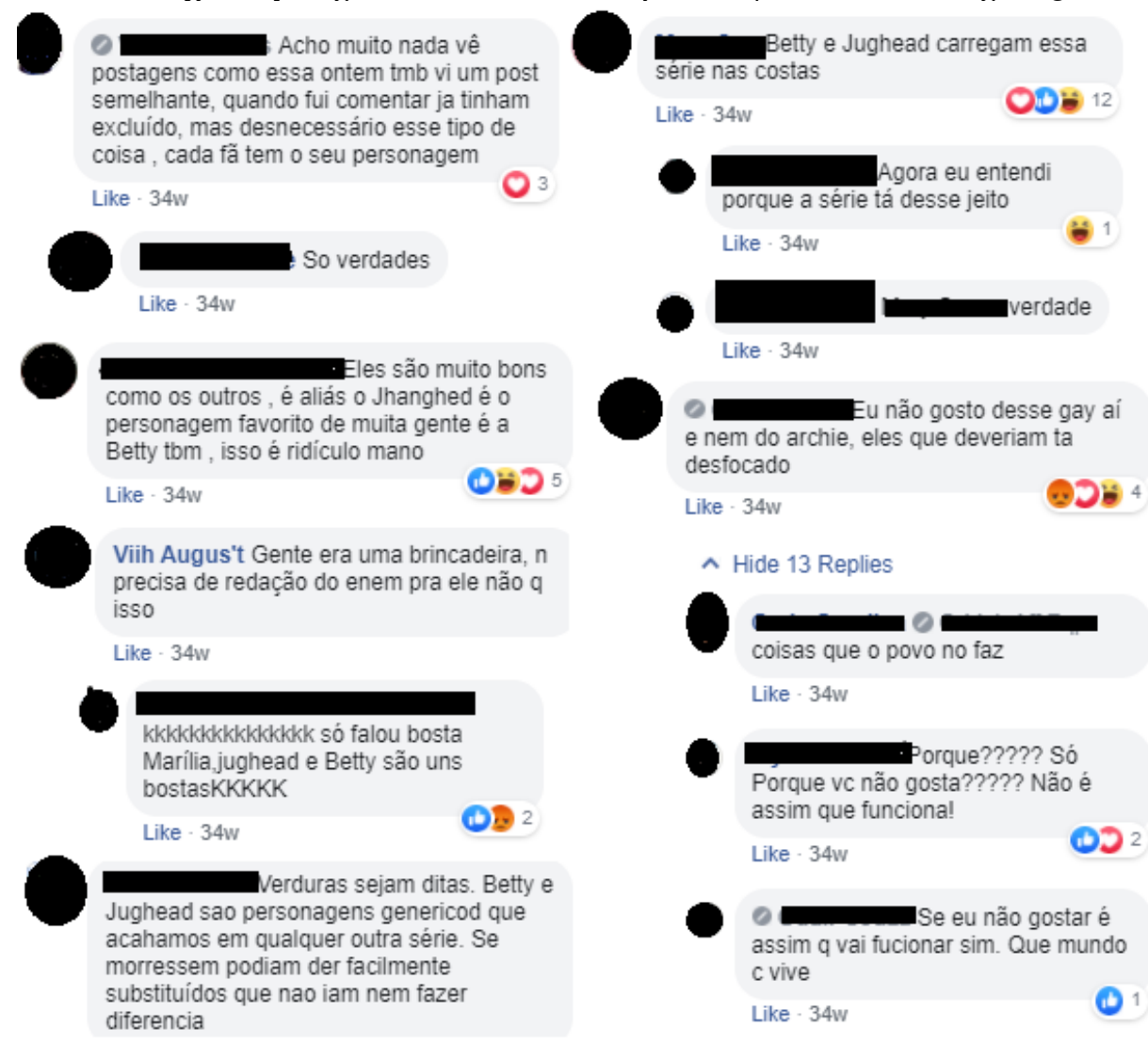

Fonte: Captura de tela da página de grupo do Facebook Riverdale Br, em setembro de $2020^{16}$

Quando o assunto é Jughead Jones, as disputas acirradas entre os dois subgrupos existem e estão constantemente emergindo, seja em uma publicação que não considera aspectos da personalidade da personagem ou questiona a sua popularidade, bem como naquelas nas quais o afeto para com Jughead é questionado.

${ }^{16}$ Link publicação original:

https://www.facebook.com/groups/RiverdaleBrasilgrupo/permalink/2492577950967048/ 
Assim, percebemos nessa comunidade o empenho do moderador como figura responsável pela manutenção da ordem entre os fãs. Ao mesmo tempo que a manifestação das opiniões não é impedida, ocorria intervenção para amenizar a gravidade dos debates. A medida é condizente com descrições de comunidades de fãs como a de Jancovich e Hunt (2002), que criticam a falsa autoafirmação dos membros da comunidade como tolerantes, quando em segunda análise o relacionamento interno do grupo se mostra repleto de disputas e intransigências. Eles afirmam que, apesar de os fãs descreverem suas subculturas como comunidades solidárias, isso é desmentido pela tentativa constante de proteger uma desejada "pureza interna”, a partir da “identificação de intrusos inautênticos que devem ser rejeitados (p. 28) - ou, nesse caso, embates que, em primeira instância, supostamente não caberiam a uma comunidade de fãs.

Ressaltamos não ser nossa intenção trazer questões como liberdade de expressão ou censura. A atuação dos moderadores se faz em função das normas de leitura obrigatória ao entrar na comunidade e, talvez por isso, suas intervenções são pouco contestadas. Consideramos, entretanto, a mediação relevante para este artigo pois ilustra noções originárias das comunidades de fãs: unir membros com interesses e afetos em comum, enaltecer o sentido de pertencimento a uma comunidade e participar de trocas com clima amistoso.

\section{Considerações Finais}

A partir dos estudos de fãs e dos elementos observados dentro do grupo de Facebook Riverdale Brasil é possível perceber que fandoms organizados se reúnem em prol de um objetivo geral que é o de estar conectado com pessoas que possuem apreço pela mesma obra - no caso aqui abordado, pela série Riverdale. A partir dos dados postos no presente artigo, pode-se pensar em como existem múltiplos caminhos da própria recepção de um grupo, que se subdivide e cria novas comunidades interpretativas dentro de seu próprio coletivo geral. No caso de Riverdale, houve inclinação aos debates em torno de personagens e relacionamentos amorosos, centrais em comunidades de fãs de séries adolescentes. O debate sobre ações, moralidades e narrativa romântica estão alinhados a demais comunidades de fãs adolescentes, configurando, portanto, aspecto a ser considerado em análises de comunidades deste tipo. 
Entre os resultados da observação da comunidade Riverdale Brasil no Facebook, destacamos, primeiramente, a importância de se compreender os fandoms organizados como espaço de interações entre indivíduos, com repertórios particulares e subjetividades distintas, ainda que unidos por afetos comuns. Acerca do exemplo da disputa entre apoiadores do personagem Jughead e seus haters, ao aprofundarmos o olhar sobre as disputas de opinião entre fãs de uma mesma série, pudemos observar que os embates estão muitas vezes ligados às práticas e atuações de cada fã dentro da comunidade.

Essa percepção ficou evidente ao destacarmos que as postagens mesclam a opinião individual do fã e uma intencionalidade, um ‘tom' de debate, apontados aqui como publicações provocativas ou opinativas, o que influencia diretamente o rumo das discussões no fandom. O desempenho individual nas postagens e comentários, como uso de ironia, ataques diretos ou tom de fala, são centrais para determinar o andamento das disputas, e devem ser considerados na pesquisa empírica sobre conflitos internos em comunidades de fãs.

Além disso, atestamos o papel dos moderadores da comunidade para que o laço que une os fãs em torno da obra de adoração seja soberano às disputas internas do grupo. Longe de apoiarmos hierarquias autoritárias dentro de grupos de fãs, acreditamos que estas atuações pontuais prezam pelam unidade afetiva do grupo, seguem normas pré-estabelecidas e são aceitas pelos membros. Assim, ramificações de olhares vão aglomerando-se, mas sem perder de vista que todos consomem uma mesma obra ou artista.

Por fim, a partir da fragmentação do olhar por diferentes pontos de vista que envolvem a disputa entre Jugheaders e Jughaters, buscamos contribuir com as explorações metodológicas no campo dos estudos de comunidades de fãs online, explorando proposta metodológica de observação dessas disputas a partir de eixos e categorias de análise. 
Referências

AKPINAR, A; WENNERSTRÖM, M. Emotional Ownership and the Fan Fiction

Community. Lund: Department of Business Administration of Lund University School of Economics and Management, 2006.

BACON-SMITH, C. Enterprising Women: Television Fandom and the Creation of Popular Myth. Philadelphia: University of Pennsylvania Press, 1992.

BARDIN, L. Análise de Conteúdo. Lisboa: Edições 70, 1977.

BORGES, G. et al. A construção de mundos ficcionais pelo fandom Limantha, de Malhação: Viva a Diferença. Em: LOPES, M. I. V. A Construção de Mundos na Ficção Televisiva Brasileira. Porto Alegre: Sulina, 2019. pp. 107-131.

BOURDIEU, Pierre. A Distinção: Crítica Social do Julgamento. 1a. Reimpressão. São Paulo: Edusp; Porto Alegre, RS: Zouk, 2008.

CARLOMAGNO, M. C.; ROCHA, L. C. Como criar e classificar categorias para fazer análise de conteúdo: uma questão metodológica. Revista Eletrônica de Ciência Política, [s.l.], v. 7, n. 1, jul. 2016.

CASTILHO, F; PENNER, T. Shippers no Twitter: práticas de fãs de ficção televisiva. Revista Lumina, v. 11, n. 2, p. 216-233, 2017.

CURI, P. Fan arts, fan fics e fan films: o consumo dos fãs e a criação de uma nova cultura. In: BAMBA, M. A recepção cinematográfica: teorias e estudos de caso. Salvador: EDUFBA, 2013.

DOURISH, P., MAZMANIAN, M. Media as material: Information, Representations as Material Foundations for Organizational Practice. In: CARLILE, P. R.; et al. (eds.) How Matter Matters. 3. ed. Oxford: Oxford University Press, 2012.

FISH, S. "Is there a text in this class?". Trad. Rafael Eugênio Hoyos. Alfa, São Paulo, v. 36, p. 189-206, 1992.

FISKE, J. The Cultural Economy of Fandom. In: LEWIS, L. A. The Adoring Audience: Fan Culture and Popular Media. London: Routledge, 1992.

GRAY, J. New Audiences, New Textualities: Anti-Fans and Non-Fans. International Journal of Cultural Studies. v. 6, n. 1. 2003; p. 64-81.

GRECO, C. Virou cult! Telenovela, nostalgia e fãs. 1. ed. Alumínio, SP: Jogo de Palavras: Votorantim: Provocare Ed., 2019. v. 1. 286 p.

JANCOVICH, M; HUNT, N. The Mainstream, Distinction and Cult TV. In: PEARSON, R. and GWENLLIAN-JONES, S. Cult Television. Minneapolis: University of Minnesota Press, 2004.

JENKINS, H. Textual poachers: television fans \& participatory culture. New York: Routledge, 1992.

JOHNSON, D. Fantagonism: factions, Institutions, and constitutive hegemonies of fandom. In: GRAY, J.; SANDVOSS, C.; HARRINGTON, C. L. (eds.) Fandom: identities and communities in a mediated world, New York University Press: New York, 2017. 
LEAL, S. R. O Fandom na televisão: uma análise da participação dos fãs na cultura contemporânea através das séries de TV. 2017. 16 f. Monografia (Especialização em Televisão e Convergência Digital) - Unidade Acadêmica de Educação Continuada, Universidade do Vale do Rio dos Sinos, 2017. Disponível em:

http://www.repositorio.jesuita.org.br/handle/UNISINOS/6784>. Acesso em: 12 ago. 2018.

LEMOS, A. Comunicação e Mediação. In: Alzamora, G; Coutinho, F.; Ziller, J. (orgs.).

Dossiê Bruno Latour. Belo Horizonte: Editora UFMG. 2019).

LOPES, M. I. V. et al. A autoconstrução do fã: performance e estratégias de fãs de telenovela na internet. In: Lopes, M. I. V. (org.). Por uma teoria de fãs da ficção televisiva brasileira. Porto Alegre: Sulina, 2015. p. 17-64

PONTES, E. L; SANTOS, C. M. O comportamento dos Fandoms a partir do ato de Shippar - Um Estudo de Caso em Once Upon a Time. In: Congresso Brasileiro de Ciências da Comunicação. 39., 2016, São Paulo. Anais eletrônicos... São Paulo: Intercom, 2016, p. 1 - 15. Disponível em:

https://portalintercom.org.br/anais/nacional2016/resumos/R11-0916-1.pdf. Acesso em: 17 de fevereiro de 2021.

REZENDE, N. NICOLAU, M. Fã e Fandom: estudo de caso sobre as estratégias mercadológicas da série Game of Thrones. In: Simpósio Nacional da ABCiber, 8., 2014, São Paulo. Anais eletrônicos... São Paulo: ESPM-SP, 2014, p. 1 - 14. Disponível em: https://abciber.org.br/simposio2014/anais/GTs/nathalia_michelle_grisi_rezende_6o.pdf. Acesso em: 17 fev. 2021.

SANDVOSS, C. Quando Estrutura e Agência se Encontram: os fãs e o poder. Ciberlegenda, n. 28., p. 08-41, 2013.

STENGEL, M.; MOREIRA, J. O.; LIMA, N. L. O amor na internet: um encontro amoroso de um adolescente. Psicologia em estudo, v. 20, n. 2, p. 319-330, 2015.

Este é um ARTIGO publicado em acesso aberto (Open Access) sob a licença Creative Commons Attribution, que permite uso, distribuição e reprodução em qualquer meio, sem restrições, desde que o trabalho original seja corretamente citado. 